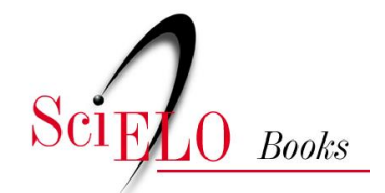

\title{
4 - The dimensions of the digital divide
}

\author{
Bernardo Sorj
}

SORJ, B.brazil@digitaldivide.com: confronting inequality in the information society [online]. Rio de Janeiro: Centro Edelstein de Pesquisa Social, 2008. The Dimensions of the Digital Divide. pp. 44-57. ISBN 978-85-99662-48-9. Available from SciELO Books <http://books.scielo.org>.

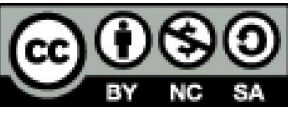

All the contents of this chapter, except where otherwise noted, is licensed under a Creative Commons Attribution-Non Commercial-ShareAlike 3.0 Unported.

Todo o conteúdo deste capítulo, exceto quando houver ressalva, é publicado sob a licença Creative Commons Atribuição Uso Não Comercial - Partilha nos Mesmos Termos 3.0 Não adaptada.

Todo el contenido de este capítulo, excepto donde se indique lo contrario, está bajo licencia de la licencia Creative Commons Reconocimento-NoComercial-CompartirIgual 3.0 Unported. 


\title{
4 - The Dimensions of the Digital Divide
}

\author{
Connected, Disconnected, and the Digital Divide
}

In modern societies, the terms "connected" and "disconnected" refer to the unequal access to a diverse collection of communication tools such as books, periodicals, radio, telephone, television, and the Internet. Although we will be focusing on access to and uses of the Internet, the digital divide cannot be disassociated from access to other communication and information technologies. There is a strong correlation between the digital divide and other forms of social inequality. Generally, the highest levels of digital exclusion are found in the lowest income sectors. In modern societies based on mass consumption, social inequality in terms of communication does not manifest itself solely only on the basis of access to material goods such as radio, telephone, television, and Internet. The intellectual and professional capacity of each user to make the most of each of these communication and information technologies is as important as access itself.

The central focus of this book is the impact of the digital divide on inequality within each society. The concept of the digital divide used in the bibliography and reports from international organizations encompasses widely differing meanings. Distinguishing the different questions and problems associated with the concept of the digital divide is necessary to avoid analytical confusions and to clearly define objectives of social policies by.

\section{The Digital Divide on an International Scale: e-readiness}

International studies seeking to develop indicators to establish a country's relative position in terms of information technology development created the concept of e-readiness. This concept evaluates the penetration of communication technologies within countries in comparison with other countries, an important factor in determining international economic competitiveness. The relative e-readiness of a country is not necessarily correlated with the country's internal digital divide, although policies that fight against the digital divide positively affect national capacity in terms of e-readiness.

There are many ways to formulate and define the e-readiness of each country. Some authors identify stages of e-readiness development; others propose formulas based on key indicators such as the number of people with access to communication technologies. More complex models consider factors including the institutional contexts, regulatory systems in the area of telecommunications, human resources, systems of innovation, and the uses and impacts on society of new technologies. The simpler formulas suffer from the types of problems that are typical of quantitative comparisons between countries with diverse economic, political, 
and socio-cultural realities. This is particularly important in this area where product dissemination and education levels determine the diversity of potential uses for new technology. The more complex formulas also have their shortcomings in that by considering qualitative dimensions, they are more difficult to quantify and they depend on adjudication of more or less random values to each index.

Despite the different criteria they use, the majority of studies arrive at a typology of levels of e-readiness that generally accompanies the scale of countries in terms of per capita income. Still, within each group of countries, there are important differences. Among the most advanced countries, the United States occupies a special position, being the country with the largest number of Internet users, home to a large number of leading software and service companies, and to the majority of the world's most popular portals and search engines. The relative advantage for U.S. companies is expected to diminish in the next years, but European and Japan linguistic diversity or specificity makes it difficult to bring their sites to international audiences.

Access to communication technology at the international level seems to reproduce the same distance as in per capita income inequality between countries. However, when we consider advanced technologies alone, the inequalities between countries is even greater than when measured in terms of per capita income. If the difference in distribution of radio and television between rich and poor countries is smaller than the differences in economic development, the availability of computers with access to the Internet is 600 times greater in the most developed and wealthy countries than in the poorest developing countries. If we consider the number of people with broadband access, this difference increases even more.

It is often argued that poor countries can jump stages of the development process by absorbing the most advanced technology. But technology is constantly changing and what appears to be cutting edge is quickly rendered obsolete. While the telephone is still unknown for a large part of the population of the planet, communication by telephone is increasingly becoming secondary to the Internet as instrument of communication. Soon, the new generation of cellular telephones will take over with devices that provide a large part of the Internet's functions in miniature form. Thus, the highly dynamic character of new technology is a barrier toward attempts to bring poor countries to the level of richer countries.

\section{The Digital Divide and Development: E-Development}

The digital divide discussion includes another subject, the use of information technology to generate economic growth, or e-development. E-development must be differentiated from the digital divide itself though it has consequences for social inequality, through the creation of employment possibilities, and reduction of poverty. It raises specific questions that will not be addressed in this book concerning the direction of investments, industrial policies, international trade, and policies for developing human resources, science, and technology. These policies also demand a legal framework including laws for the protection of privacy, 
copyright laws, protections against electronic crime, laws governing the uses of cryptographic systems, regulations for commerce and for authentication of electronic signatures, and consumer rights specific legislation.

International and national institutions have touted the Internet as an instrument for modernizing small and medium-sized businesses, and as a mechanism for accessing international markets. Since Internet use by tourists in developed countries is practically universal, nearly all governments and many hotels in developing countries have web sites aimed at this audience. In many of the poorest developing countries, a large part of publicly and privately runs web sites are for the promotion of tourism.

An important theme in this area is the impact of the new technologies on the flow of payments between developed and developing countries and its consequences not only on development but also on the digital divide. While the international telephone payment system favors developing countries for receiving more calls than they make, the payment systems for information transfer via the Internet favor developed countries, primarily the United States, the main center of international of Internet traffic.

\section{The Digital Divide and Social Inequality}

The digital divide represents a dimension of social inequality: it measures the relative level of access to products, services, and benefits of new information and communication technologies between different segments of the population. The digital divide also addresses another subject associated with social inequality that it cannot be confused with the digital divide itself, that is, information technology as a tool in the fight against poverty. In situations of economic growth it is possible to reduce poverty indicators (the size of the population below a set poverty line), while simultaneously increasing social inequality. Thus the fights against inequality and poverty have much in common but are not synonymous.

As with all new social innovations, the impact of information technology will in principle increase social inequality because its initial impact reaches only the wealthiest sectors of the population. Thus, the fight against the digital divide is not so much a fight to diminish social inequality as it is an effort to prevent inequality from increasing because of the advantages that those groups of the population with more resources and education enjoy as a result of exclusive access to this information technology

The many methods for evaluating the size of the digital divide take in consideration the distribution of varied communication media, education levels and types of use of digital contents. As in the case of e-readiness there are innumerable formulas to measure the digital divide and, as in the previous case, they present the same types of problems. Instead of arguing in favor of a particular method of measurement, we will discuss the diverse dimensions of the digital divide. 


\section{The Dimensions of the Digital Divide}

The digital divide depends on five factors that determine the level of equality of access to information technology systems: 1) the existence of physical infrastructure for transmission; 2) the availability of connection equipment such as a computer, modem, and access line; 3) training in the use of the computers and the Internet; 4) intellectual capacities and the social insertion of users (this is the product of the educational and intellectual level, profession and the social network that determines the effective use of information and the necessities of Internet communication; 5) the production and use of specific contents adapted to the needs of the diverse segments of the population. While first the two criteria refer to passive dimensions of Internet access, the last three dimensions define areas of potential active appropriation.

The distinction, between the different levels of access and use, is basic to development of methodologies for evaluating, accompanying, and acting in the fight against the digital divide. Starting at the first, each successive level is a prerequisite for the next. Public programs aimed at universal communication services focus primarily on the first and second levels of physical infrastructures and connection equipment that are only part of the preconditions for transforming the Internet into a public service.

Below is a more detailed description of each of the different levels:

Access Infrastructure - Access infrastructures are comprised of transmission systems that can function by way of telephone, satellite, radio, cable television and electricity wires. In the future it will be possible to access the Internet by way of cellular telephones and digital television (although digital TV will not allow effective interactivity, and requires connection to an Internet provider). Internet connections can be at either normal or broadband levels, which determine the speed of information transfer. The availability of both systems is dependent upon the existence of local providers with equipment for these services.

It is important to mention that the competitiveness of the different access technologies has been evasive and that billions dollars of investments (for example in satellites) have been lost for backing the wrong technologies, supported by inaccurate forecasts of market trends. The same thing could occur with the prognosis on the convergence of third generation mobile telephony technologies $(3 \mathrm{G})$, of the telephone, digital television and Internet, which are expected to lead to the abandonment of the current model of personal computer (PC). This trend may be real but it is still far from materializing and a clear definition of its format has not yet emerged.

The universalization of access infrastructures is a process that is practically complete in advanced countries, though there are still some more isolated regions of the United States and various regions of the European Union where broadband is still not available. In developing countries, on the other hand, the universalization of infrastructures is still a central problem, 
particularly in rural areas. In the developing world, broadband is generally only available in large and some medium-sized cities. In the majority of developing countries, the Internet is a phenomenon that is concentrated primarily in urban centers, in particular large cities.

The ongoing introduction of new information technologies contributes to the creation of a permanent gap in the social cycle of products, both internationally and nationally. As indicated previously, at each stage of technological innovation, developing countries make an effort to reach the advanced countries, but when they are nearly successful, a new technology replaces the enormous technological distance. For example, now that the telephone is starting to be universally available in emerging industrial countries, the challenge has become access to the Internet, and in turn as the access the Internet starts to spread, broadband presents a new challenge. The acceleration of technological innovation means that we must consider thinking the digital divide as dynamic, with parameters that are modified with each new innovation in information technology systems. When most production of Internet content will be aimed at users with broadband access or long-term connections, slow speed users will become excluded.

Equipment for individual access - The most common equipment for accessing the Internet is a computer with a modem and a telephone line with a dialup access to a service provider. The main mechanisms of individual access are: home, work, school and public or private tele-centers. In low-income sectors without equipment or access services, access to the Internet depends on collective access points such as school, work, or tele-centers.

The literature on the digital divide is generally consistent in defining two main factors that determine Internet access levels, given the existence of communication infrastructure. They are personal income and educational level. Given the same income level, people with higher education levels are more likely to have access to the Internet. With the exception of some particular regions, there is relative equality of Internet access between men and women. The unequal impact on different racial and ethnic groups tends to be consistent with inequalities in income and education, with the exception of some situations where unequal access is aggravated by language differences between ethnic groups. The penetration of the Internet in developing countries is also associated to the level of urbanization. The digital divide, particularly in the developing countries, is aggravated dramatically in rural regions. In general, higher levels of urban concentration correspond to higher numbers of users.

The digital divide has a strong age component that is more pronounced among low-income sectors. The likelihood of a person being computer and Internet literate decreases with age. The difficulty of learning at a later age and the high concentration of illiteracy among older populations, cause the digital divide, to be particularly large among low-income older adults in developing countries.

For some authors it is necessary to distinguish between active users, for whom the Internet is integrated into daily life, and passive users, for whom Internet use is casual. The number of computers and users registered to Internet access providers is the principal means for measuring the number of users. The diversity of methods of access makes it difficult to count 
the number of Internet users. There is great disagreement regarding the criteria for evaluating the number of users, even within the United States, between the different organizations and companies specialized in the business. In principle, one assumes that the number of users per access point (computer connected to the Internet) is larger in developing countries than in developed countries and that poor families have more users per computer than rich families (where families have more than one home computer connected to the Internet). In some cases, a single user can be registered with multiple providers, in other cases, as in the telecenters, a single computer provides access to a great numbers of users. When Internet access penetrates the poorest sectors of the population, the number of users per computer tends to increase.

The policies of infrastructure access expansion, oriented by the privatization and competition generating telecommunications policies of the 1990's have been generally successful, but in all developing countries they have collided with the limits of effective demand. The poorest members of the population do not have the resources to buy a computer and are even less able to pay monthly fees for a telephone line and Internet access provider. The most common mechanisms for addressing this barrier to universal access are: 1) price subsidies for the lowincome users, 2) promotion of low-cost or recycled computers, 3) support for the creation of tele-centers.

A) Price subsidies - This is an area that still lacks convincing solutions. The international experience offers examples of reduced access rates in poor neighborhoods, tele-centers with free or subsidized access fees, and subsidized rates that favor low-income users and telecenters.

B) Promotion of low-cost and recycled computers - The production of cheap computers, sometimes associated with subsidized financing, has not yet produced relevant results according to the digital divide literature. Critics argue that these computers generally are inferior in terms of data storage and speed. Some simplified computers, without hard drives, are designed for users with broadband access that can pay connection costs, which is not within the reach of good part of the population. Another approach, the recycling of used computers for distribution to technology centers in low-income areas, has some successful experiences on the international level through the donation of used computers to poor countries.

The production of "people's computers" has as its main challenge the creation of a product capable of confronting the "double helix" of the computer industry: the need for constant renewal of the hardware required by the new software increasing demand of information storage and processing capacity. There are several possibilities for how the production of such a computer could happen: 1) the development of an alternative computer through joint efforts of public research centers and national enterprises in developing countries; or 2) the production of a cheaper computer by the multi-national industry. In the latter case the problem is that a low-cost computer could take a share away from the existing market. One possible solution would be to target only the institutional market (schools and public 
organizations) and tele- centers in low-income areas. In addition to efforts to reduce hardware costs, it would be necessary to find alternative solutions to lowering the costs of the software.

Tele-centers - Tele-centers are collective access points where users can benefit from Internet services using equipment that does not belong to them. Tele-centers are the primary response to the difficulties with obtaining universal access and play a role comparable to that of the public telephone for people without their own telephone. Tele-centers are the main instrument for advancing universal access in developing countries.

Despite the importance given to tele-centers, the bibliography details only a small number of documented examples of successful experiences. Paradoxically, or perhaps not, it is the most developed countries where there have been the largest number of tele-centers experiments designed to address the requirements of the most needy communities.

In addition to responding to the needs of users without the means for individual access, telecenters enable investment by providers in areas where the individual consumption capacity is low but through the aggregated demand, providing access can become a viable and relevant commercial market for Internet service providers. In general, telecommunications regulating agencies, due to limitations of their mandates or other factors, tend not to regulate access fees that could make tele-centers services viable.

International organizations have developed several typologies of tele-centers. They can be simplified in the following models:

Access providing tele-centers, provide basic access such as Internet, fax, photocopying, printing and telephone service. In Africa, in particular, the tele- centers often provide only telephone service

Single purpose technology centers, which offer a single type of content and services, such as governmental or educational information

Training tele-centers, that include courses in information technology use and user support along with the services mentioned in the first type,

Multipurpose community tele-centers, that offer several of the following services: local access, information, public services, educational courses, technology courses, community radio, content production, and services for the community.

Training - Training in the use of the computer and the Internet (called digital literacy or eliteracy) can be offered through formal courses in school or at work, private courses, or courses promoted by non-governmental organizations, or by spending time in contexts (schools, work or home) where the Internet is used and people nearby are able to offer assistance when needed. Children, in particular, tend to learn to use computers and the Internet through play without direct orientation. 
The probability of having the type of access that allows this kind of learning by osmosis, either at home or work, is lower in low-income sectors where the chances of owning a home computer as well as having access to a computer in the work are extremely low.

Intellectual skills of the user - The ability to use the information available on the Internet as source of knowledge and intellectual and professional development, depends on the users prior skills. This qualification assumes basic literacy and abilities acquired within the school system. Digital literacy cannot be dissociated from book literacy. The network multiplies the possibilities for intellectual and professional work but at least until the present moment, it is not a substitute for the basic intellectual qualifications that are acquired at school and its effective potential depends on them. Thus social inequality expressed thorough education is reproduced and increases with use of the Internet. As long as much of the population of the developing world continues to struggle with illiteracy and semi-literacy, universal access the Internet, will be an illusory goal.

\section{The Impact of Digital Services}

The aforementioned factors combine in determining the uses for information technology, the most important criteria for evaluating its effective relevance for society. These uses depend on the creative appropriation of the new technology by the different social actors and each user's creative development, producing new contents and applications that represent innovative responses to economic, social political, and cultural problems.

e-communication - The uses of the Internet can be analyzed according to its dual dimensionality as both an instrument of communication and dissemination of information and an instrument for access to information. Its potential as a communication instrument (email) is greater among high income users since most of the members of the user's network have access to the Internet, while this is not normally the case of low income users. This is even truer in the case of international contacts, because low-income sectors are very unlikely to have an international social network. The only relevant exception relates to poor families with members working abroad, often illegally, for whom the Internet offers cheap communication and contact with their native land and families.

e-education - Distance education precedes the Internet. Correspondence courses followed by radio, television and videocassette, have a long tradition and have served innumerable people, who, due either to time or distance, could not attend a traditional class. In 1969 the Open University, in Great Britain, had a pioneering role in university level education by way of correspondence courses. In the 1980's and 1990's several developing countries created higher education distance education courses, especially for inhabitants of rural areas. Today distance universities in Turkey, China, Indonesia, Thailand, Korea and India have hundreds of thousand of students each. 
In the majority of distance universities established in developing countries the main means of communication are the post office, radio, television, videotapes and CDs, with the Internet still playing, in general, a supporting role. One of the obvious reasons for the limited use of the Internet is that the majority of students lack access. This situation is starting to change and in the past few years, nearly the majority of the principal universities in developing countries have begun to conduct distance education via the Internet. Courses are often at the graduate level and participants are generally professionals who are unable to participate in traditional courses.

While local universities seek to enter the distance education market, large universities of the developed world, in particular the United States (but also from Spain in Latin America), have entered into the distance education business, often in partnerships with local private universities with courses supported by the prestige of the university of origin. Tuition for these programs is often higher than that of local universities but the level of quality control often leaves much to be desired.

Distance education has been defended as a solution for schoolteachers training problems, especially in rural areas. There are several cases in developing countries of the creation of regional training using the Internet and videoconferencing, and school nets that offer teachers continuously updated programs and didactic material. The success of these initiatives depends on the availability of Internet access in schools and on the basic training of the teachers in the use of the Internet. Among countries that have made advancements in the creation of schoolnets are Chile (with the Enlace program supported by a network of universities that already reaches almost all secondary schools and more of the half of primary schools), South Africa, and Thailand.

Since most of the children in developing countries can only access computers in schools, it is fundamental that computers be available into schools even if they are concentrated in collective laboratories. This allows children to become socialized in computer and Internet use, offering a minimum of familiarity with information technology and increasing their future chances in the market place.

e-science and technology - The Internet was originally a tool used by the scientific community and spread rapidly among the most advanced developing countries including the majority of Latin America, China, India, Egypt, and South Africa. It has already spread in the poorest countries, generally with the support of international organizations, foundations, and corporations. For the scientific communities of developing countries, access to the Internet has meant the possibility for easy, fast, and cheap communication with the international scientific community and online access to databases and virtual libraries to which they do not have material access. The Internet facilitated the scientific interchange and participation in specialized international networks.

e-culture - In the field of culture one the most important impacts of the Internet has been the creation of virtual libraries, that allow populations of developing countries that are financially unable to construct and to maintain traditional libraries, to access the written assets of 
humanity. Although access to these texts by computer screen is neither equivalent, nor a substitute to paper based text, virtual libraries allow contact with texts that would otherwise be unavailable to students at schools and universities in the developing world.

The Internet has great potential as a vehicle for expression of the cultural diversity of the contemporary world and for making cultural works available across the world. The creation of virtual museums has advanced substantially in some developing countries in particular in Latin America followed by some Asian countries like Korea, China, and Turkey, as well as South Africa. The use of the Internet for developing cultural tourism and publicizing artistic events is now a well-established practice.

e-health - The Internet is often presented as the solution for remote regions and/or for regions of developing countries that lack sufficient local medical staffing. Although there is an enormous potential for this use, there are limited possibilities for success in the near future, because the regions with the greatest needs are those with the least access to resources and staff trained for using the instruments of telemedicine, with their continuing high costs. This area is a low-priority for health care systems in developing countries.

The Internet has already been introduced for modernizing administration systems and organization of health care systems in developing countries, leading to more rational resource management and improving the quality of the services. Information technology is also used to control epidemics, for participation in international monitoring, to make the body of medical literature available via virtual libraries, and to distribute information between health care professionals, particularly in public health campaigns.

e-government - In developing countries, e-government can be an important instrument for reducing the inefficiency and the private appropriation of the state by way of bureaucracies that transform public services into sources of favors, gratuities and systematic corruption. The ability to access an increasing number of documents and official information via the Internet eliminates the power of the bureaucratic and political intermediary.

However, to the extent that public state services are accessible via the Internet, they tend to create an increasing divide between citizens with and without access. This problem will be aggravated with the widespread use of public services via the Internet. Since the universalization of Internet access in developing countries will be a long process, it will be necessary to maintain alternative lines of communication between the government and citizens, such as telephone and face-to-face contact.

Social content - The contents available on the Internet constitute a decisive area in the dynamics of the digital divide. The uses that they enable are central factors in the impact of the Internet on social inequality. Even if universal access is assured, the lack of specific contents can limit the effective impact of the Internet on low-income sectors.

Generally, in both developing and developed countries a large part of Internet contents are developed for the middle class target market, the principal market with the potential to 
indirectly or directly generate revenues for web sites, either through advertising, by buying advertised products, or by direct payment for access. The orientation toward middle class users is evident in both form and content as the majority of the sites assume a relatively high user educational level. Even non-commercial home pages tend to be produced by the middle class, since making a web site requires certain knowledge of the Internet or a minimum of financial resources.

The shortage of contents specifically created for rural communities is aggravated by the fact that the Internet is basically an urban phenomenon. Users and especially producers of web sites are in large majority concentrated in large urban centers. In small cities and in lowincome neighborhoods of large cities, the production of information concerning local necessities (such as job and housing announcements) is very limited.

For some time, the main concern associated with the global impact of Internet content production was the predominance of English language sites. In addition to imposing an Anglo-Saxon cultural hegemony, English language sites were socially exclusive as much because of their contents (not relevant to local conditions), as because they require knowledge of English. In non-English speaking regions, this skill is usually limited to the upper classes.

This concern has been shown to be an exaggeration: as the Internet grows the percentage of home pages in each language tends to be consistent with the percentages of Internet users (with exception of most Asian languages and ethnic minorities). Still international inequalities continue to be important. International Internet traffic indicators show that Latin American users consult web sites in advanced countries many times more often than the reverse and, that, while growth in the number of sites in developing countries has accelerated, in comparative terms, most sites still leave much to be desired in terms of quality and the amount of the information they offer (this can be easily confirmed by visiting sites of many of the governments of central Africa). The importance of the quantity information available on English language web sites means that those who lack English language abilities have a limited capacity to make use of the Internet. In the future, instantaneous text translation systems (many of which already are available but do not yet produce high quality translations) will be important instruments in the intra-cultural communication and dissemination of information on a global level.

The existing literature indicates a shortage of sites aimed at minority ethnic indigenous groups in developing countries, and has shown that where these sites do exist, they tend to be produced by outside specialists. The shortage of sites dedicated to the needs of poor urban sectors of the population, whose main point of access are the tele-centers, is equally dramatic. These groups, which are the first line of potential users of Internet, much more than in rural areas, have limited e-content produced with consideration toward their cultural and socioeconomic necessities. 


\section{Box E - Policies for Combating the Digital Divide}

E-social development does not substitute other kinds of social development, nor does the fight against the digital divide substitute the set of other measures necessary for facing poverty, social inequality, and one of their most terrible consequences, urban violence. But edevelopment has become one of the dimensions of development, as the fight against the digital divide is one of many dimensions of the fight against poverty and social inequality.

The criteria for assessing efforts to combat the digital divide must be the value of these programs for reducing other forms of social inequality and poverty. In the past decade, the United States has practically achieved universal access to the Internet but social inequality did not diminish because of this, in fact it increased. Japan, the country with the second highest number of people with Internet access, has been unable to overcome economic stagnation that has continued for over a decade

The increasing complexity associated with the fight against the social inequality creates new challenges for strategic planning of governmental actions and for the development of social policies. Policies aimed at reducing the digital divide are a necessary component of social policy but they are not the answer to all the social and economic problems. The same is true in relation to e-education and to the problems brought on by declines in school performance. The introduction of Internet should be part of the general rethinking of teaching methods and the role of both school and teachers. The search for simplistic solutions is constant in developing countries and international agencies. The Internet is too important to be brought into the cycle of miracle cures that later are abandoned for not meeting unrealistic expectations.

In the first place, developing countries should take into consideration the dynamic nature of the digital divide, which demands that countries that are not part of the central nucleus of technology generation develop at least the capacity for defensive strategic analysis. This will allow them to follow the trends and experiences of information technology leaders in developed world and relevant experiences in developing countries, thereby reducing the experimentation costs and helping to define the best technological options and most appropriate products for their social realities.

Second, policies must assure the coherence, integration, security and interoperability of different public services, controlling costs and making government action more coherent. The coordination of the policies cannot be left to short sighted party interests and the institution responsible for defining the strategies for the information society must be part of the central core of government. If the decision-making nucleus of the government does not commit to the coordination of ministerial activities associated to the information society, the result will be waste due to duplicated efforts and unrealistic programs. The fight against the digital divide must be viewed as long term state policy, avoiding the tendency in developing countries for new governments to abandon and devalue the accomplishments of their predecessor. 
Third, a lack of coordination between the activities of different international and national cooperation agencies, each with its own agenda related to the digital divide, often leads to duplicating efforts. Fragmentation and institutional isolation causes not only waste of resources, but also affects the learning process on how to confront the digital divide.

Fourth, is necessary to increase the coordination of infrastructure development policies and the synergy between different physical networks such as roads, electric lines, telephone and fiber optics. Universal service should be promoted, either by creating incentives so that the private companies invest directly in the most needy areas, or, if needed, intervening directly to assure services at accessible costs.

Fifth, the urgency in resolving the problems of the digital divide cannot justify the massive hasty investments in areas that demand experimental pilot programs, adequate local conditions, users training, systems of evaluation and technical support. This is particularly true of the installation of Internet access in schools and tele-centers.

Sixth, investments in collective access must be accompanied by preparation of local human resources. If there is nobody to provide help in making use of transmitted information, the investment in communication infrastructure and access equipment is wasted. The Internet allows access to excellent educational programs for remote areas, but this possibility does not resolve the problem of shortages of teachers with a minimum education (typical of many remote places). Qualified teachers are necessary for making good use of the available material in the Internet.

Seventh, an international effort to constantly evaluate, systematize and disseminate existing experiences of tele-centers for low-income areas is needed in order to go beyond anecdotal material presented in the bibliography on the digital divide. These evaluations should include technological alternatives, types of software, models of management, systems of payment, services offered, and types of partnership between NGOs and the private and public sectors, and forms of integration with the local community.

Eighth, it is necessary to advance policies that assure the development of tele-centers. Specific regulations should ensure that communication services operators and Internet service providers offer public institutions and tele-centers in low-income areas access to infrastructure at reduced cost. The models of tele-centers must be adapted to the diverse local contexts, and should be developed directly by the public sector supported by nongovernmental organizations and enterprises. The creation of public access points should creatively combine a variety of types of tele-centers. For example, a model can be imagined where in a particular neighborhood or small village, some collective access points are installed by the private initiative while a public multi-purpose tele-center offers courses, orients the population in Internet use, and supports efforts to produce local content with information on the life of the community. 
Finally, as the second part of this book attempts to demonstrate, confronting the digital divide requires creative partnerships between non-governmental organizations, companies, and government, in which the non-governmental organization and enterprises play an important role as source of innovation and contracted services, without taking responsibility away from the state. The fight against the digital divide depends, above all, on the capacity of state action to use market impulses and the experiences non-governmental organization pilot programs, to assure that poor sectors of the population are integrated into and participate in the construction of the global society. 